\title{
Direct preparation of fatty acid methyl esters and determination of in vitro antioxidant potential of lipid from fresh Sebal causarium Seed
}

\author{
Olubunmi ATOLANI ${ }^{1}$, Oluwaseeni ADENIYI ${ }^{2}$, Oluwatimilehin O. KAYODE ${ }^{2}$, Charles B. ADEOSUN ${ }^{2}$ \\ ${ }^{1}$ Department of Chemistry, University of Ilorin, P.M.B. 1515, Ilorin, Nigeria. \\ ${ }^{2}$ Department of Chemical Sciences, Redeemer's University, P.M.B. 3005, Mowe, Nigeria.
}

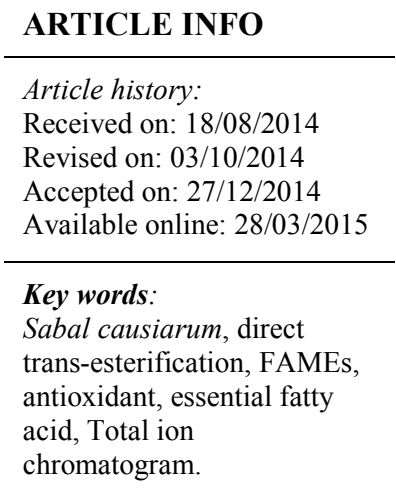

\begin{abstract}
Classical method of sample preparation for fatty acid analysis is a complicated, rigorous, multiple-step process that is often time-consuming. However, innovation has made it possible to obtain fatty acids esters in a single step without compromise of the quality and quantity of the products obtained. Fatty acid methyl esters (FAMEs) were obtained from Sabal causiarum seed using direct trans-esterification method. The reaction was performed in a one necked glass reactor equipped with a reflux condenser. The composition of the FAMEs obtained was analyzed using GC-FID/GC-MS. The FAMEs was also evaluated for its antioxidant potential using DPPH assay while $\alpha$ - tocopherol served as a standard. From the Total ion chromatogram, a total of twelve fatty acids were identified with the dominant being linoleic acid (29.83\%), an essential polyunsaturated omega- 6 fatty acid. Other compounds obtained in significant yield include palmitic acid $(20.75 \%)$, dodecanoic acid $(12.15 \%)$, oleic acid, an omega-9 monounsaturated fatty acid (11.51\%), 11-Octadecenoic acid (5.89\%), Ceric acid (4.97) and lignoceric acid (4.56\%). The oil had higher antioxidant potential (with $\mathrm{IC}_{50}$ value $0.19 \pm 0.31 \mathrm{mg} / \mathrm{mL}$ ) than the standard, alpha-tocopherol (with $\mathrm{IC}_{50}$ of $0.25 \pm 0.4(\mathrm{mg} / \mathrm{mL})$. The direct trans-esterification method enables the quick determination of the fatty acid profile of Sabal causiarum seed. It is a viable method that saves time, limit use of solvents and reduce the possibility of contaminations that is associated with classical multistage procedure. The chemical composition and high antioxidant value of the oil is a strong indication of the future economical and biological relevance of the Sabal causiarum seed oil.
\end{abstract}

\section{INTRODUCTION}

The relevance of fatty acids (FAs) in human diet and health cannot be overemphasized. The human brain is estimated to be nearly 60 percent fat (Chang et al., 2009). Moreso, essential fatty acids (EFAs) usually of plant origin plays vital roles in the maintenance of optimal health and brain functions (Singh, 2005). FAs and EFAs have been demonstrated to regulate lymphocyte proliferation and metabolism (Otton et al., 1998), enhance the immune system (Yaqoob et al., 1998; Granato et al., 2000), induce increased granulocyte macrophage-colony (Bahramian et al., 2004), induced cell death in T cells, macrophage cells and also enhance autoimmunity (Zhang et al., 2004; Martinsdelima et al., 2006). FAs has been reported to possess antioxidant activity (Atolani et al., 2012), anti-inflammatory activities (Calder, 2005) and anticancer activity (Robinson et al., 2002). Sabal causiarum, also known as Puerto Rican hat palm belongs to the family of

\footnotetext{
* Corresponding Author

E-mail: atolanio@run.edu.ng
}

flowering plant called Arecaceae. It is of the subfamily Coryphoideae and the tribe Sabaleae (Roncal et al., 2008). The plant is also known as palma de escoba in Puerto Rico (Proctor, 2005). In Puerto Rico, Sabal causiarum grows in the subtropical moist forest zone (Ewel and Whitmore 1973). Common associates are Cedrela odorata L., Delonix regta (Bojer) Raf., Erythrina poeppigiana (walp.) and Tabebuia heterophylla (DC). Sabal causiarum flowers in the months of April through August. The species is however not endangered (Zona, 1990). Four glycosides were initially isolated from the leaves of Sabal causiarum (Idaka, et al., 1988). Recently, a bioactive compound, A [25ethyl,23-methyl-19-nor-24-methylene-3,4-seco-4(28)-lanosten-10, 3-olide (the first 19-nor lanostane derivatives of the 3,4-seco type with a spiro element) has also been isolated from the leave (El-Dib et al., 2004). To the best of our knowledge, there is no record of the fatty acid composition of the underutilized tropical seed (of Sabal causiarum) till date. The immense relevance of FAs in human health prompts the investigation of the antioxidant and fatty acid composition of Sabal causiarum seed. 


\section{EXPERIMENTAL}

\section{Plant Material}

Sabal causiarum seeds were collected in a fruiting season from trees within the neighborhood of Redeemer's University, Ogun State, Nigeria. The plant was taxonomically identified by a botanist at the Herbarium of the Botany Department of the University of Lagos, Lagos, Nigeria where a voucher specimen, LUH 6063 was deposited.

\section{Solvents and Reagents}

Solvents and chemicals used which includes hexane, benzene, methanol, aluminuim chloride, sulphuric acid, sodium sulphate, 1,1-Diphenyl-2-picrylhydrazyl (DPPH) and $\alpha$-tocopherol were of analytical grade, and where necessary, solvents were redistilled before use.

\section{One-step Extraction and Trans-methylation of Lipid from Plant Matrix}

$15 \mathrm{~g}$ of fresh flower sample was refluxed with $100 \mathrm{~mL}$ of a mixture containing Methanol: Benzene: Hexane: Aluminuim chloride: Sulphuric acid in a ratio (37:20:36:5:2) for 30 minutes in a one neck-flask. The resulting mixture was allowed to cool and then filtered.

The supernatant was separated in a separating funnel and the organic layer washed with distilled water to neutrality. The organic layer was concentrated to obtain the transmethylated product: fatty acid methyl esters (FAMEs) and the yield noted. The method which afforded the extraction, hydrolysis and methylation of the lipid in a single procedure is a slight modification of the method previously described (Garces and Mancha, 1993).

\section{DPPH Free Radical Scavenging Activities}

The free radical scavenging activity of the extracted fatty acid methyl esters from flower was examined in vitro using the 1,1-Diphenyl-2-picrylhydrazyl (DPPH) assay. The spectrophotometric assay was carried out according to the method previously described (Adeosun et al 2013; Atolani et al., 2012). The DPPH free radical was freshly prepared at a $0.1 \mathrm{mM}$ concentration in methanol and protected from light. Stock solutions of the FAMEs $(1 \mathrm{mg} / \mathrm{mL})$ was prepared and diluted to final concentrations of $1000,500,300,200,100,50$ and $5 \mu \mathrm{g} / \mathrm{mL}$ in methanol.

$1 \mathrm{~mL}$ of $0.1 \mathrm{mM}$ DPPH methanol solution was added to solutions of the sample as well as the standard ( $\beta$-tocopherol) and incubated for 30 minutes in the dark. The absorbance was determined at $517 \mathrm{~nm}$. Blank experiment was also carried out to determine the absorbance of DPPH before interacting with the sample. The percentage antioxidant activity (\%AA) was obtained as percent DPPH radical scavenging, which was calculated using the equation:

$$
\% \mathrm{AA}=100 \times\left[\left(\mathrm{Abs}_{\text {control }}-\mathrm{Abs}_{\text {sample }}\right)\right] /\left(\mathrm{Abs}_{\text {control }}\right)
$$

Where $\mathrm{Abs}_{\text {control }}$ is the absorbance of the control and $\mathrm{Abs}_{\text {sample }}$ is the absorbance of the sample at $517 \mathrm{~nm}$.

The $\mathrm{IC}_{50}$ was determined on GraphPad Prism 3 software (San Diego, USA) through a non-linear regression analysis using the dose-response inhibition curves. $\mathrm{IC}_{50}$ was defined as the concentration of the sample that scavenged $50 \%$ of the DPPH free radicals. Results are presented as mean \pm standard error of the mean.

\section{Determination of the FAMEs Composition}

The gas chromatogram was obtained on an Agilent Technology 7890A gas chromatograph GC-FID, equipped with a fused silica capillary column HP-5MS (30 m by $0.32,0.5 \mu \mathrm{m}$ film thickness) on ultra-pure helium gas and coupled to a mass selective detector (mass spectrometer). The injector and interface were operated at 250 and $380{ }^{\circ} \mathrm{C}$ respectively. The oven temperature was raised from 60 to $270{ }^{\circ} \mathrm{C}$ at a heating rate of $5{ }^{\circ} \mathrm{C}$ $\min ^{-1}$ and then held isothermally. The sample was injected in a splitless mode using 7683 series Agilent Technologies injector. The percentages of the compounds were obtained by GC-FID analysis.

Mass spectrometry MS, Qualitative analyses were carried out on a MS 5975, msd Agilent Technologies operated at an ionization voltage of $70 \mathrm{eV}$ over an acquisition mass range under the experimental conditions reported for GC-FID analysis. The chemical compositions of the product obtained were identified by comparison of their MS spectral with data obtained from National Institute Standard and Technology (NIST, 2008) database. The relative percentages of the constituent compounds were percentages from the GC peak areas based on the total ion chromatogram.

\section{RESULTS AND DISCUSSION}

The direct Transmethylation (DTM) adopted in this study has been reported to afford an improved recovery of total fatty acids in comparison to classic multistep method (Bligh and Dyer, 1959; Dickey et al, 2002). The classical multistep method, besides consuming time also required the use of relatively large amount of solvents for the derivatization to facilitate the analysis and quantification of fatty acid methyl esters by gas chromatography. The classical method being a multiple steps procedure increases the possibility of contamination and sample losses which are significantly minimized in the DTM (Fig. 1).

The direct methylation combines extraction and transesterification into one step, thereby giving rise to a simpler and faster analysis whilst consuming less solvent (Indarti et al., 2005; Meier et al., 2006). The method results in a better recovery of the total fatty acid methyl ester present in the sample without bias or selectivity toward any lipid classes (Dickey et al, 2002). Extraction with organic solvents is known to be majorly efficient if the plant samples are first dried and crunched (Cooney et al., 2009), but the DTM eliminate the entire drying process. 


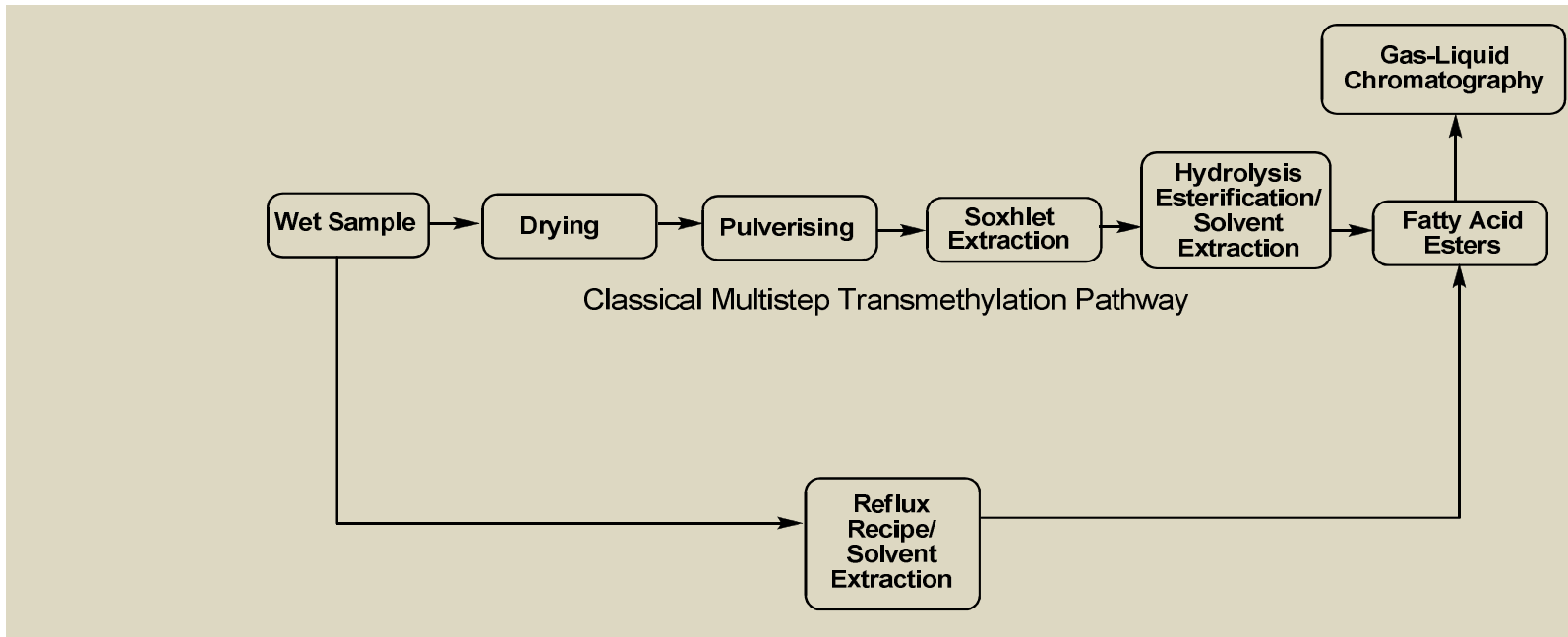

Direct Transmethylation Pathway

Fig. 1: Comparison of the Classic Multistep and Direct Transmethylation Procedure.

Additionally, the use of conventional solvent extraction methods on samples such as fish condiment and highly pigmented plant material usually results in the recovery of many pigments and other lipid-soluble materials that contribute to the crude total lipid and thereby confound the estimate of total fatty acid content (DeKoning et al. 1985). It has been reported that the DTM procedure conforms to the U.S. Nutritional Labeling and Education Act (NLEA) demand (Xiao, 2010). The recipe used in this study contains hexane and benzene as solvent, sulphuric acid as for hydrolysis, aluminium chloride as catalyst and methanol for methylation. The FAMEs were thus obtained in a single procedure with a yield, $0.63 \%$ of the total seed weight.

\section{Fatty Acids Composition}

The GC-MS result of the fatty acid composition of the oil obtained from the Sabal causiarum seed is shown in Table 1. A total of twelve fatty acids were identified from the total ion chromatogram of the GC. The ratio of the total unsaturated to saturated fatty acids is approximately 1:1. Monounsaturated accounted for about $19.2 \%$ while polyunsaturated accounted for about $29.8 \%$ of total fatty acids. The dominant fatty acid was Linoleic acid (C18:2) in a concentration of $29.83 \%$. It is the only polyunsaturated omega- 6 fatty acid. Other major fatty acids include palmitic acid (20.75\%), dodecanoic acid (12.15\%), oleic acid, an omega-9 monounsaturated fatty acid (11.51\%), 11Octadecenoic acid (5.89\%), Ceric acid (4.97) and lignoceric acid (4.56\%). The most abundant FA being linoleic acid is a polyunsaturated omega- 6 fatty acid which has significant importance in human diet (Singh, 2005). However, some report have suggested that certain high level of certain omega -6 fatty acids relative to certain omega-3 fatty acids may trigger the onset of disorder in human body (Okuyama et al., 2006). Apart from biological relevance of the linoleic acid it is also of great industrial application since it serves numerous oleochemical uses in pharmaceuticals, oil paints, varnishes, lubricants, cosmetics and surfactants (Beltran et al., 2004).

Table 1: Fatty acids profile of Sabal causiarum seed oil obtained from the GCMS

\begin{tabular}{|c|c|c|c|}
\hline $\begin{array}{l}\text { Peak } \\
\text { No. }\end{array}$ & Fatty Acids & $\begin{array}{c}\text { Retention } \\
\text { Time (Min) }\end{array}$ & $\begin{array}{c}\% \\
\text { Yield }\end{array}$ \\
\hline 1 & Dodecanoic acid (12:0) & 8.48 & 12.15 \\
\hline 2 & Palmitoleic (16:1) & 12.62 & 1.89 \\
\hline 3 & Palmitic acid (16:0) & 12.92 & 20.75 \\
\hline 4 & Margaric acid (17:0) & 13.83 & 1.59 \\
\hline 5 & Linoleic acid $(18: 2 \omega-6,9)$ & 14.55 & 29.83 \\
\hline 6 & Stearic acid $(18: 0)$ & 14.80 & 5.38 \\
\hline 7 & Oleic acid $(18: 1 \omega-9)$ & 14.94 & 11.51 \\
\hline 8 & 11-Octadecenoic acid (18:1) & 15.02 & 5.89 \\
\hline 9 & Behenic acid acid (22:0) & 18.13 & 0.99 \\
\hline 10 & Tricosanoic acid (23:0) & 18.89 & 0.49 \\
\hline 11 & Lignoceric acid (24:0) & 19.68 & 4.56 \\
\hline \multirow[t]{4}{*}{12} & Ceric acid $(26: 0)$ & 21.70 & 4.97 \\
\hline & Total Saturate & & 50.88 \\
\hline & Monounsaturate & & 19.29 \\
\hline & Polyunsaturate & & 29.83 \\
\hline
\end{tabular}

Margaric acid (1.59\%), Behenic acid (0.99\%) and tricosanoic acid $(0.49 \%)$ were found to be less dominant saturated fatty acids while palmitoleic acid, an omega- 9 fatty acid was also detected at low concentration (1.89\%).

Margaric acid, though not commonly observed in natural products has been reportedly identified in the volatile of Annona reticulate (Pino et al., 2003), and Pourouma guianensis (Lopes et al., 1999) as well as in the hexane extract of the aerial parts of Aristolochia acutifolia (Palmeira et al., 2001). Palmitic acid, oleic acid, linoleic acid, stearic acid, behenic acid, margaric acid and Lignoceric acid have also been reported as constituent of virgin olive and Crambe abyssinica seed oil (Beltran et al., 2004; Lalas et al., 2012). 


\section{DPPH Free Radical Scavenging Activities}

The result of the in vitro DPPH free radical scavenging activities of the FAMEs (Table 2) indicated that the antioxidant activity of the FAMEs from the seed of Sabal causiarum with $\mathrm{IC}_{50}$ of $0.19 \pm 0.31(\mathrm{mg} / \mathrm{mL})$ was more significant than the standard, $\alpha$ - tocopherol with $\mathrm{IC}_{50}$ of $0.25 \pm 0.4$ $(\mathrm{mg} / \mathrm{mL})$. This suggests a possible synergistic action of the FA present in the seed oil. Synergistic antioxidant activities of fatty acids from other plants have been reported before (Atolani et al., 2012, 2013). The ability of the FAMEs to scavenge the DPPH radical is an indication that the plant could be useful in slowing down the progress of oxidative stress. This therefore adds credence to the possible application of the plant in biological system.

Table 2: Result of the Antioxidant Activities.

\begin{tabular}{ll}
\hline Sample & IC50 $(\mathbf{m g} / \mathbf{m L})$ \\
\hline FAMEs & $0.19 \pm 0.31$ \\
$\alpha$ - Tocopherol & $0.25 \pm 0.40$ \\
\hline Values are mean of duplicate data obtained &
\end{tabular}

Values are mean of duplicate data obtained.

\section{CONCLUSION}

Direct trans-esterification of fatty acid from the seed of Sebal causarium and GC-MS analysis has enabled the quick identification of the various fatty acids in the seed in a simple procedure. The one-step extraction procedure seems efficient, time saving and economical in the analysis of FAs in the seed of Sebal causarium. The GC-MS result indicated twelve fatty acids with the most prominent being Linoleic acid, an essential polyunsaturated fatty acid. The antioxidant activity of the oil from the underutilized tropical seed also indicated that the seed could be a viable natural renewable source of antioxidant compounds. More work would be needed to further establish the biological and economical potentials of the lesser known tropical seed.

\section{CONFLICT OF INTEREST}

Authors declare no conflict of interest.

\section{REFERENCES}

Adeosun CB, Sinmisola S, Opeifa AO, Atolani O, Essential oil from the stem bark of Cordia sebestena Scavenged Free Radicals. Journal of Acute Medicine, 2013; (3): 138-141.

Atolani O, Olatunji GA, Fabiyi OA, Adeniji J. A. and Ogbole OO, Phytochemicals from Kigelia pinnata Leaves show Antioxidant and Anti-cancer potentials on Human Cancer Cell Line. Journal of Medicinal Food, 2013, 16 (10): 878-885.

Atolani O, Omere J, Otuechere CA, Adewuyi A, Antioxidant and cytotoxicity effects of seed oils from edible fruits. Journal of Acute Disease, 2012; 1 (2): 130-134

Bahramian N, Ostergren-Lunden G, Bondjers G, Olsson U, Fatty acids induce increased granulocyte macrophage-colony stimulating factor secretion through protein kinase C-activation in THP-1 macrophages. Lipids, 2004; 39: 243-249.

Beltran G, Rio CD, Sánchez S, Martínez L, Influence of Harvest Date and Crop Yield on the Fatty Acid Composition of Virgin Olive Oils from Cv. Picual. J. Agric. Food Chem, 2004; 52 (11): 3434-3440.
Bligh EG, Dyer WJ, A rapid method of total lipid extraction and purification. Canadian Journal of Biochemistry and Physiology, 1959; 37: 911-917.

Calder PC. Polyunsaturated fatty acids and inflammation. Biochem. Soc. Trans, 2005; 33: 423-427.

Chang CY, Ke DS, Chen JY, Essential fatty acids and human brain. Acta Neurol Taiwan, 2009; 18 (4): 231-41.

Cooney M, Young G, Nagle N, Extraction of bio-oils from microalgae. Sep Purif Rev, 2009; 38(4):291-325.

DeKoning AJ, Evans AA, Heydenrych C, Purcell CJ, Wessels $\mathrm{JPH}$, A critical investigation of a number of different methods of lipid determination in fish meal, with particular emphasis on corrections required in these determinations. Journal of Science and Food Agriculture, 1985; 36: 177-1 85 .

Dickey L.A., Teter B.B., Sampugna J. and Woons L.C. Comparison of a direct transesterification method and the Bligh and Dyer method to determine fatty acid content in striped bass tissue and diet, North American Journal of Aquaculture, 2002; 64: 158-163.

El-Dib R, Kaloga M, Mahmoud I, Soliman HS, Moharram FA, Kolodziej H. Sablacaurin A and B, two 19-nor-3,4-seco-lanostane-type triterpenoids from Sabal causiarum and Sabal blackburniana, respectively. Phytochemistry, 2004; 65(8):1153-7.

Ewel JJ and Whitmore JL. 1973. The ecological life zones of Puerto Rico and the U.S. Virgin Islands. U.S.D.A. Forest Serv. Res. Paper ITF-I8, Washington, DC. 72 p.

Garces R. and Mancha M. One-step lipid extraction and fatty acid methyl esters preparation from fresh plant tissues. Analytical Biochemistry, 1993; 211(1): 139-143.

Granato D, Blum S, Rossle C, Le-Boucher J, Malnoe A, Dutot G. Effects of parenteral lipid emulsions with different fatty acid composition on immune cell functions in vitro. JPEN, J. Parenter. Enteral Nutr, 2000; 24: 113-118.

Idaka K, Hirai Y, Shoji J. Studies on the Constituents of Palmae Plants. 4. The Constituents of the Leaves of Sabal causiarum Becc. Chemical \& Pharmaceutical Bulletin, 1988; 36(5): 1783-1790.

Indarti E. Majid M. I. A., Hashim R. and Chong A. Direct FAME synthesis for rapid total lipid analysis from fish oil and cod liver oil, Journal of Food Composition and Analysis, 2005; 18: 161-170.

Lalas S, Gortzi O, Athanasiadis V, Dourtoglou E, Dourtoglou V, Full Characterisation ofCrambe abyssinica Hochst. Seed Oil. Journal of oil and fat industries, 2012; 2253-2258.

Lopes D, Koketsu M, Carauta JPP, de-Oliveira RR, Kaplan MAC, Chemical composition of Pourouma guianensis Aublet essential oils Flavour Fragr. J. 1999; 14: 233-236.

Meier S Mjos,S.A., Joensen,H. and Grahl-Nielsen O. Validation of a one-step extraction/methylation method for determination of fatty acids and cholesterol in marine tissues, Journal of Chromatography A, 2006; 1104: 291-298.

Okuyama H, Ichikawa Y, Sun Y, Hamazaki T, Lands WEM, $\omega 3$ Fatty Acids Effectively Prevent Coronary Heart Disease and Other LateOnset Diseases - The Excessive Linoleic Acid Syndrome. In Okuyama, H. Prevention of Coronary Heart Disease. World Review of Nutrition and Dietetics; 2006: 83-103.

Otton R, Graziola F, Souza JA, Curi TC, Hirata MH, Curi R, Effect of dietary fat on lymphocyte proliferation and metabolism. Cell. Biochem. Funct; 1998: 16, 253-259.

Palmeira SF, Conserva LM, Andrade EHA, Guilhon GMSP, Analysis by GC-MS of the hexane extract of the aerial parts of Aristolochia acutifolia Duchtr. Flavour Fragr. J, 2001; 16: 85-88.

Pino JA, Marbot R, Fuentes V. Characterization of volatiles in Bullock's heart (Annona reticulata L.) fruit cultivars from Cuba J. Agri. Food Chemistry, 2003; 51: 3836-3839.

Proctor GR. 2005. Arecaceae (Palmae). In Acevedo-Rodríguez, Pedro; Strong, Mark T. Monocots and Gymnosperms of Puerto Rico and the Virgin Islands. Contributions of the United States National Herbarium. pp. 149-50.

Robinson LE, Clandinin MT, and Field CJ, The role of dietary long-chain n-3 fatty acids in anti-cancer immune defense and R3230AC 
mammary tumor growth in rats: influence of diet fat composition. Breast Cancer Research and Treatment. 2002; 73: 145-160.

Roncal J., Zona S, Lewis CE, Molecular Phylogenetic Studies of Caribbean Palms (Arecaceae) and Their Relationships to Biogeography and Conservation. The Botanical Review, 2008; 74 (1): 78-102.

Singh M, Essential fatty acids, DHA and human Brain. Indian Jounal of Pediatric, 2005; 72: 239-242.

Xiao L. 2010. Evaluation of Extraction Methods for Recovery of Fatty Acids from Marine Products. Master thesis of EMQAL project. University of Bergen. Norway. Pp. 4-17.

Yaqoob P, Knapper JA, Webb DH, Williams CM, Newsholme EA, Calder PC, Effect of olive oil on immune function in middle-aged men. Am. J. Clin. Nutr, 1998; 67: 129-135.

Zhang J, Xu XM, Liu Y, Activation-induced cell death in T cells and autoimmunity. Cell. Mol. Immunol, 2004; 1: 186-192.
Zona S. A monograph of Sabal (Arecaceae: Coryphoideae). ALISO, 1990; 12 (4): 583-666.

\section{How to cite this article:}

Olubunmi ATOLANI, Oluwaseeni ADENIYI, Oluwatimilehin O. KAYODE, Charles B. ADEOSUN. Direct Preparation of Fatty Acid methyl Esters and Determination of in vitro Antioxidant Potential of Lipid from Fresh Sebal causarium Seed. J App Pharm Sci, 2015; 5 (03): 024-028. 